\title{
Analysis of knowledge, attitude and behavior of oncology medical staff in palliative care
}

\author{
Xianmei $\mathrm{Wu}^{1}$, Xin Zhang ${ }^{1}$, Jing Zhang ${ }^{3}$, Xiaowei Cui ${ }^{2}$ \\ ${ }^{1}$ Department of Breast Surgery, ${ }^{2}$ Second Head and Neck Ward, Harbin Medical University Cancer Hospital, Harbin 150081, China; ${ }^{3}$ Seven Wards \\ of General Surgery, the Second Affiliated Hospital of Harbin Medical University, Harbin 150001, China \\ Contributions: (I) Conception and design: X Wu, X Cui; (II) Administrative support: X Zhang; (III) Provision of study materials or patients: X Wu, \\ J Zhang, X Cui; (IV) Collection and assembly of data: All authors; (V) Data analysis and interpretation: X Wu, X Zhang, X Cui; (VI) Manuscript \\ writing: All authors; (VII) Final approval of manuscript: All authors. \\ Correspondence to: Xiaowei Cui. Second Head and Neck Ward, Harbin Medical University Cancer Hospital, Harbin 150081, China. \\ Email: cuixiaowei10@sina.com.
}

Background: The incidence of cancer has risen as the population has grown older. For patients with advanced cancer and limited survival, palliative care (PC) is especially urgent and important. In this study, we analyzed the knowledge, attitude, and behavior of oncology medical staff in PC at one hospital.

Methods: A questionnaire ("knowledge, Attitude and Behavior Questionnaire for PCs of Oncology Medical Staff”) designed to investigate 167 oncology members of medical staff serving at the Affiliated Tumor Hospital of Harbin Medical University in China. After obtaining the consent of the respondents, a pair of questionnaires were sent and recovered.

Results: (I) Awareness survey of oncologist medical staff members on PC of the four issues, the awareness part with Q2 (PC service should not be provided with cancer treatment at the same time) the highest accuracy, Q1-Q4 all correct proportion of 39.61\%; (II) the majority of the oncology medical staff members questioned $(73.38 \%$ ) believed that when patients can no longer accept surgery, radiotherapy, chemotherapy and other anti-cancer treatment, when a patient's symptoms cannot be controlled (55.19\%), or when estimated survival time is $<3$ months $(57.76 \%$ ), PC service should be accepted. Meanwhile, $28.57 \%$ of oncology medical staff believed that they would recommend PC to tumor patients on their first visit to the hospital, $18.83 \%$ thought that patients should be informed of the prognosis information, and $40.26 \%$ indicated that they were more willing to inform the patient's family/caregiver of the diagnosis and prognosis. In relation to behavior, more than half of respondents said that when conflict arises between patients who would prefer to stop receiving life-sustaining treatment and their family members, the will of the patient should be followed, while the implementation of cardiopulmonary resuscitation for patients with advanced tumors is situation-dependent. When the patient was no longer capable of making a decision and the intention of the family members was inconsistent with the patient's previously expressed preferences, $38.31 \%$ of the respondents claimed they would support the patient.

Conclusions: Members of oncology medical staffs have insufficient PC knowledge, and they should pay close attention to their knowledge, attitude, and behavior in relation to PC.

Keywords: Oncology medical staffs; palliative care (PC); knowledge; attitude; behavior

Submitted Mar 02, 2020. Accepted for publication Apr 26, 2020.

doi: $10.21037 / \mathrm{apm}-20-851$

View this article at: http://dx.doi.org/10.21037/apm-20-851 


\section{Introduction}

Palliative care (PC) used to be called "palliative care". As a combination of medical technology and humanities, it was first defined as "research and management of patients with active and advanced diseases and limited survival period in the 1980s, and its core is care for quality of life". Its objects are mainly malignant tumors (such as advanced malignant tumors) and non-tumor (such as the late stage of chronic congestive heart failure and chronic obstructive pulmonary disease) $(1,2)$. PC not only pays the greatest attention to and alleviates the physical pain and provides the patients with necessary psychological comfort, which benefits the patients and their families, but also helps the medical staff to improve the specialty facing the dying patients, reduce the invalid medical resources, which benefits the hospital and even the country (3). With the aging of the population, the incidence of tumor diseases is also increasing. For the patients with limited survival in the late stage of cancer, PC is particularly urgent and important $(4,5)$. In recent years, with the promotion of non-governmental organizations and governments, PC in China has been developing continuously. However, in developing countries, including Mainland China, personal PC services have increased, but compared with western countries, PC Services in mainland China have not attracted widespread attention $(6,7)$. For China, the lack of public education, backward policies and regulations, and the lack of awareness of medical staff on PC hinder the further development of PC, while the lack of awareness of medical staff on PC services has become the main obstacle to the development of PC. Today, with the aging accelerating, the cognition and attitude of cancer medical staff towards PC are of great significance to promote the development of PC $(8,9)$. This study aimed to collect relative data and use descriptive analysis to investigate the knowledge, attitudes, and practices of members of oncology medical staff in the PC field at a Chinese hospital, which may provide reference for the promotion of PC services. We present the following article in accordance with the SURGE reporting checklist (available at http://dx.doi.org/10.21037/apm-20-851).

\section{Methods}

\section{Survey participants}

Between July 2018 and August 2018, oncology medical staff members from the Affiliated Tumor Hospital of Harbin Medical University were selected for investigation using an objective sampling method.

\section{Survey tools}

A self-made questionnaire, comprising two parts, was used in this study. The first part requested personal information, including age, gender, job title, education, job nature, and details of working life. The second part comprised a self-made "knowledge, attitude and behavior of oncology medical staffs on PC questionnaire", according to the literature (10). The questionnaire contained 15 questions:

- Q1-Q4 addressed the knowledge of oncology medical staff on PC, with 3 options: right, wrong, and unknown;

* Q5-Q11 focused on understanding the respondents' attitudes towards PC, disease information disclosure, and the delivery of bad news (of these questions, Q5 was multiple choice and Q6-Q11 were single choice;

* Q12-Q15 surveyed behavior, mainly in relation to decision-making.

The questionnaire items were determined by 7 PC experts based on literature review and discussion. The content validity and surface validity were acceptable. In the study of $\mathrm{Gu}(10)$, its kappa value is 0.85 , and its reliability is good. Based on the pre-survey, 10 staff members were selected to answer 2 surveys with interval of 2 weeks at the Affiliated Tumor Hospital of Harbin Medical University. The consistency of the 2 pre-surveys (Kappa $>0.85$ ) indicated the high reliability of the questionnaire.

\section{Survey methods}

A questionnaire was sent to the oncology staff members to obtain their informed consent; the prior consent of the directors and head nurses of each department in the hospital had been obtained. The participants anonymously completed the questionnaire within a set time of 10 minutes. The investigator recovered the questionnaires after completion, and confirmed there were no omissions or logical errors and that they had been filled out correctly. All data were entered by the investigator using Epidata dual entry mode and kept confidential. Finally, the data were analyzed by another investigator who did not participate in the data entry process.

\section{Statistical analysis}

Statistical analysis was carried out with SPSS 19.0 software. 
Table 1 Awareness survey of oncologist medical staff members on PC (n, \%)

\begin{tabular}{|c|c|c|c|}
\hline Question & Knowledge & Correct numbers & Percentage (\%) \\
\hline Q1 & Different people have different views on palliative care & 138 & 89.61 \\
\hline Q2 & PC services should not be provided simultaneously with anti-cancer treatment & 143 & 92.86 \\
\hline Q3 & Patients who receive PC services must accept death & 84 & 54.55 \\
\hline Q4 & PC services are the same as hospice care & 130 & 84.42 \\
\hline
\end{tabular}

PC, palliative care.

The characteristics of the respondents were described as n (\%).

\section{Results}

\section{General information of surveyed oncology medical staff} members

Among the 167 oncology medical staff members at the hospital, 154 agreed to participate in the survey and were each sent one questionnaire, all of which were effectively recovered. Males and females accounted for $24.68 \%$ (38/154) and $75.32 \%(116 / 154)$ of the respondents, respectively, and they ranged in age from 20 to 67 (average age: $38.27 \pm 5.64$ ) years old. The respondents had acquired between 2 and 24 years of medical service (average time: $11.9 \pm 2.87$ years) and between 3 and 20 years of oncology work (average time: $8.8 \pm 2.17$ years). There were 65 doctors $(42.20 \%)$ and $89(57.80 \%)$ nurses. Among the respondents were $22(33.85 \%), 26(40.00 \%), 10(15.38 \%)$, and 7 (10.77\%) doctors, residents, attending physicians, deputy directors physicians and chief physicians, respectively; and among the 89 nurses, were 48 (53.93\%), 20 (22.47\%), 12 $(13.48 \%)$, and $9(10.11 \%)$ primary nurses, supervisors, deputy chief nurses, and chief nurses, respectively. In terms of education level, junior college, undergraduate, master, and higher education accounted for $14.94 \%(23 / 154)$, $59.09 \%$ (91/154), 20.77\% (32/154) and 5.19\% (8/154); PC education had previously been received by $9.09 \%(14 / 154)$ of all participants.

\section{Awareness survey of oncologist medical staff members on PC}

The accuracy rate was $54.55-92.86 \%$, Q2 "PC services should not be provided with anti-cancer treatment at the same time" showing the highest accuracy rate. The number of correct responses for Q1-Q4 was 61, accounting for
$39.61 \%$ (Table 1).

\section{Survey on the attitude of oncology medical staff members towards $P C$}

More than half of the staff members surveyed thought that patients should start to receive PC services when they can no longer accept surgery, radiotherapy, chemotherapy and other anti-cancer treatment, or when their symptoms become uncontrollable and they have an estimated survival time $<3$ months. Less than one-third of the respondents would recommend PC to cancer patients on their first visit, and $18.83 \%$ thought patients with a poor prognosis should be informed, while more than one-third thought that this is situation-dependent. The majority of respondents believed that the attending physician should disclose information to the patient, while more than one-third were willing to inform the diagnosis and prognosis to the patient's family or caregiver themselves (Table 2).

\section{Survey on the behavior of oncology medical staff in PC}

Of the respondents, $54.55 \%$ believed that a patient's request to give up life-sustaining treatment should be followed, and $58.44 \%$ thought that the implementation of cardiopulmonary resuscitation (CPR) for patients with advanced tumors depends on the situation. When conflict arises between the patient and their family in the decisionmaking process, $52.60 \%$ of the oncology medical staff members surveyed believed that the will of the patient should be followed. In cases where the patient is no longer capable of making a decision and the intention of the family members is inconsistent with wishes previously expressed by the patient, $38.31 \%$ of the staff members surveyed stated that they would support the patient, while $32.47 \%$ of them thought that it depended on the specific situation (Table 3). 
Table 2 Survey of attitudes of oncology medical staff towards PC

\begin{tabular}{|c|c|c|}
\hline Attitude & Numbers & Percentage $(\%)$ \\
\hline When the tumor is first diagnosed & 50 & 32.47 \\
\hline When patients can no longer receive anti-tumor treatment such as surgery, radiotherapy, or chemotherapy & 113 & 73.38 \\
\hline When the patient's symptoms cannot be controlled & 85 & 55.19 \\
\hline When the patient asks for palliative care & 63 & 40.91 \\
\hline When estimated survival time is $<3$ months & 89 & 57.79 \\
\hline When estimated survival time is $<6$ months & 53 & 34.42 \\
\hline Other conditions & 14 & 9.09 \\
\hline Unsure & 92 & 59.74 \\
\hline \multicolumn{3}{|l|}{ Q7 Do you agree that PC can improve patient survival? } \\
\hline Yes & 83 & 53.90 \\
\hline No & 11 & 7.14 \\
\hline Unsure & 60 & 38.96 \\
\hline \multicolumn{3}{|l|}{ Q8 Do you think early palliative care can significantly improve patients' quality of life? } \\
\hline Yes & 111 & 72.08 \\
\hline No & 10 & 6.49 \\
\hline It depends on family/caregiver's will & 22 & 14.29 \\
\hline It depends on the situation & 68 & 44.16 \\
\hline \multicolumn{3}{|l|}{ Q10 Who do you think should disclose information to patients? } \\
\hline Attending physician & 133 & 86.36 \\
\hline Family/caregivers & 33 & 21.43 \\
\hline Social volunteer & 4 & 2.60 \\
\hline Others & 4 & 2.60 \\
\hline \multicolumn{3}{|l|}{ Q11 Who would you prefer to inform about diagnosis and prognosis? } \\
\hline Patients & 12 & 7.79 \\
\hline Family/caregivers & 62 & 40.26 \\
\hline It depends on the patient's wishes & 38 & 24.68 \\
\hline It depends on the family's/caregiver's wishes & 42 & 27.27 \\
\hline
\end{tabular}

$\mathrm{PC}$, palliative care. 
Table 3 Survey on the behavior of oncology medical staff members in PC

\begin{tabular}{|c|c|c|c|}
\hline Question & Behavior & Numbers & Percentage (\%) \\
\hline \multirow{3}{*}{ Q12 } & Yes & 84 & 54.55 \\
\hline & No & 10 & 6.49 \\
\hline & Unsure & 60 & 38.96 \\
\hline \multirow{3}{*}{ Q13 } & Yes & 11 & 7.14 \\
\hline & No & 53 & 34.42 \\
\hline & It depends on the situation & 90 & 58.44 \\
\hline \multirow[t]{2}{*}{ Q14 } & \multicolumn{3}{|c|}{ In cases of conflict between the will of a patient and that of their family, who do you think should be supported? } \\
\hline & It depends on the situation & 44 & 28.57 \\
\hline \multirow[t]{4}{*}{ Q15 } & \multicolumn{3}{|c|}{$\begin{array}{l}\text { If the patient is no longer capable of making their own decisions but has previously expressed their will and it conflicts } \\
\text { with that of their family, who should be supported? }\end{array}$} \\
\hline & Patient & 59 & 38.31 \\
\hline & Family & 45 & 29.22 \\
\hline & It depends on the situation & 50 & 32.47 \\
\hline
\end{tabular}

PC, palliative care.

\section{Discussion}

Despite the ability of medical technology to prolong the lives of cancer patients, some patients eventually succumb to their illness. As an emerging medical concept and practice, PC significantly differs from conventional medical care due to its emphasis on patients and improving their quality of life as well as its respect for patient's subjectivity. PC protects the patient's dignity, reduces the patient's economy, develops the relationship between doctors and patients, shows positive effects and effectively responds to social concerns in the medical field $(11,12)$. In China, the promotion of PC has been limited and is affected by many factors such as the national cultural environment, traditional concepts, medical education system, laws and regulations, and ethics; nevertheless, it is the lack of knowledge on PC among oncologists that is one of the most common obstacles for high-quality PC services $(13,14)$. The results of our survey showed that only $39.61 \%$ of the respondents in the awareness survey items (Q1-Q4) were all correct, suggesting that the respondents were short of knowledge about PC-much lower than the result in reports abroad $(15,16)$. This may be attributed to factors such as insufficient attention to PC in domestic medical education and the lack of a targeted and comprehensive legal system. Furthermore, the survey participants' knowledge was also lower than in previous domestic reports, which may due to the regional differences between the surveys.

Members of oncology medical staff are the implementers of the PC, whose attitude towards PC is the key factor in promoting the progression of PC. In this study, most respondents tended to recommend $\mathrm{PC}$ to cancer patients when patients could no longer receive anticancer treatments such as surgery, radiation therapy, and chemotherapy. This finding indicated that most of the oncologists believed that they have sufficient ability to deal with the symptoms of cancer patients, so when treatment options still exist, they prefer not to refer patients to PC experts. Combined with insufficient knowledge of PC, some oncologists even regard $\mathrm{PC}$ as an abandonment of treatment, which might also be an important reason why they do not tend to refer patients to PC (17). Although more than half of the respondents agreed that PC can improve patient survival and quality of 
life, only $28.5 \%$ of them would recommend PC treatment to cancer patients on their first visit, which also suggested that integrated education of PC should not only focus on patients themselves but also be targeted at physicians. Other than providing patients with a basic education of $\mathrm{PC}$, the education of oncology medical staff members to improve their knowledge and attitude towards PC could also promote $\mathrm{PC}$ development.

Disease information disclosure, especially how to deal with disease information, is also an important part of PC services. However, oncology medical staff often encounter conflict between themselves and medical teaching, cultural values, the will of patients, and family needs or spiritual beliefs in their daily work. It is a great challenge for medical personnel to disclose the diagnosis and prognosis publicly to patients especially in China, because they are faced with family-centric decisions (18). Most doctors usually disclose the diagnosis results to tumor patients in Northern Europe and the United States, but in China, it is stipulated in "People's Republic of China Tort Liability Law" that medical personnel should explain the patient's condition and the medical measures required, and if it is not appropriate to explain these directly to the patient, then they should explain to their close relatives with relatives written consent. This regulation is perhaps more in line with China's national conditions, but it also means medical personnel need to disclose disease information to some degree. Previous studies surveyed 60 oncologists and found that $40.5 \%$ of respondents believed that patients with advanced disease should be told the truth $(19,20)$. In this study, $86.36 \%$ of oncologist medical staff members considered the attending physician as the suitable person to inform the patient of the diagnosis results, but only $18.83 \%$ of respondents thought that patients should be informed of the diagnosis and treatment results of their disease. This finding suggests that it is also necessary to establish a more complete legal system that is more consistent with national conditions and conducive to promoting PC development.

In our survey, more than $54.55 \%$ of responders believed that the patient's will should be followed when they express a preference to give up life-sustaining treatment, although $38.96 \%$ chose to consider each person's physical and psychological condition, and religious and cultural background before making a decision. The results of Q13-Q15 showed that $58.44 \%, 28.57 \%$, and $32.47 \%$ of respondents, respectively, believed the decision depends on the situation, which further suggests that Chinese oncologists face a dilemma in having to respect the wishes of patients and their family members. Whether the views of family members are mostly consistent or inconsistent with the patients' views need further analysis. Advance directives, as a legal document, allow competent patients to provide appropriate guidance on the health care they wish to receive should they become incapable of making their own decisions (21), which can effectively avoid this dilemma and is widely advocated in Western countries, such as the United States, Canada, and the Netherlands. However, there are few reports about advance directives in Asia and most of these focus on investigating patients' attitudes and behaviors towards it, with little research carried out on doctors. In particular, in mainland China, advance directives have not been legalized (22).

Therefore, first of all, PC education and training should be strengthened to enhance awareness of PC in doctors. On the one hand, the status of $\mathrm{PC}$ in the medical education system is constantly improved, PC compulsory courses, continuing education courses and assessment mechanism are established, so that cancer medical staff and other medical staff can receive regular PC education, providing the basis for providing high-quality PC services. On the other hand, we should learn from the experience of foreign PC construction to expand the PC curriculum in medical colleges. In the United States, the vast majority of hospitals and colleges offer PC courses as a regular course for undergraduates and postgraduates (23). In China, more than a dozen universities, including Peking Union Medical College, Peking University Medical Department, China Medical University and West China Medical University, have successively opened PC courses, mainly for undergraduate or postgraduate elective courses. In the future, the coverage of PC in hospital schools needs to be continuously expanded. Secondly, in combination with China's specific national conditions and traditional culture, we should draw lessons from foreign legislations and cases to establish a perfect PC law and regulations system, so as to provide legal protection for doctors' reasonable operation, remove their concerns about the defendant's going to court due to "no rescue", and improve doctors' acceptance of PC. Finally, the clinical practice of PC should be strengthened through lectures, group discussions, case studies, film watching and role playing. However, our study was not without limitations. For example, the respondents lacked representativeness because only oncology medical staff members of the Affiliated Tumor Hospital of Harbin 
Medical University were involved and some concepts need in-depth exploration. So that more can be learned about PC-related information, further education and investigation should be carried out, and the relevant factors of specific problems should be further analyzed.

In summary, the oncology medical staffs we surveyed had relatively insufficient knowledge of $\mathrm{PC}$, along with some problems relating to behavior and attitude; these should be carefully addressed and further investigation and analysis should be conducted. Ultimately, educational programs to improve the knowledge, attitudes, and behaviors of oncology medical staff in PC are urgently needed.

\section{Acknowledgments}

Funding: None.

\section{Footnote}

Reporting Checklist: The authors have completed the SURGE reporting checklist. Available at: http://dx.doi. org/10.21037/apm-20-851

Data Sharing Statement: Available at: http://dx.doi. org/10.21037/apm-20-851

Conflicts of Interest: All authors have completed the ICMJE uniform disclosure form (available at: http://dx.doi. org/10.21037/apm-20-851). The authors have no conflicts of interest to declare.

Ethical Statement: The authors are accountable for all aspects of the work in ensuring that questions related to the accuracy or integrity of any part of the work are appropriately investigated and resolved. The study was approved by the Research Ethics Committee the Second Affiliated Hospital of Harbin Medical University (ky2019-7).

Open Access Statement: This is an Open Access article distributed in accordance with the Creative Commons Attribution-NonCommercial-NoDerivs 4.0 International License (CC BY-NC-ND 4.0), which permits the noncommercial replication and distribution of the article with the strict proviso that no changes or edits are made and the original work is properly cited (including links to both the formal publication through the relevant DOI and the license). See: https://creativecommons.org/licenses/by-nc-nd/4.0/.

\section{References}

1. Saga Y, Enokido M, Iwata Y, et al. Transitions in palliative care: conceptual diversification and the integration of palliative care into standard oncology care. Chin Clin Oncol 2018;7:32.

2. Beasley A, Bakitas MA, Edwards R, et al. Models of non-hospice palliative care: a review. Ann Palliat Med 2019;8:S15-21.

3. Fang B, Filippiadis D, Zeiger OM, et al. Percutaneous palliative care interventions in the cancer patient. Chin Clin Oncol 2019;8:66.

4. LaVigne AW, Gaolebale B, Maifale-Mburu G, et al. Palliative care in Botswana: current state and challenges to further development. Ann Palliat Med 2018;7:449-54.

5. Kelley AS, Morrison RS. Palliative Care for the Seriously Ill. N Engl J Med 2015;373:747-55.

6. National Consensus Project for Quality Palliative Care. Clinical practice guidelines for quality palliative care. Kans Nurse 2004;79:16-20.

7. Bidet G, Daoust L, Duval M, et al. An Order Protocol for Respiratory Distress/Acute Pain Crisis in Pediatric Palliative Care Patients: Medical and Nursing Staff Perceptions. J Palliat Med 2016;19:306-13.

8. Lee SY, Chen CH, Huang GC, et al. Factors Associated with Attitude and Knowledge Toward Hospice Palliative Care Among Medical Caregivers. Int J Gerontol 2015;9:98-102.

9. Pan HH, Wu LF, Hung YC, et al. Long-Term Effectiveness of Two Educational Methods on Knowledge, Attitude, and Practice Toward Palliative Care Consultation Services Among Nursing Staff: A Longitudinal Follow-Up Study. Clin Nurs Res 2018;27:483-96.

10. Gu X, Cheng W. Chinese oncologists' knowledge, attitudes and practice towards palliative care and end of life issues. BMC Med Educ 2016;16:149.

11. Zimmermann C, Swami N, Krzyzanowska M, et al. Early palliative care for patients with advanced cancer: a clusterrandomised controlled trial. Lancet 2014;383:1721-30.

12. Smith S, Brick A, O'Hara S, et al. Evidence on the cost and cost-effectiveness of palliative care: a literature review. Palliat Med 2014;28:130-50.

13. Tao X, Ning XH. Survey on the Accompanying Experience of Palliative Hospice Volunteers in Peking Union Medical College Hospital. Zhongguo Yi Xue Ke Xue Yuan Xue Bao 2018;40:395-400.

14. Liu X. Opinions on caring for elderly peaceful relief. Chinese Journal of Clinical Healthcare 2017;20:625-8. 
15. Miller SC, Lima JC, Thompson SA. End-of-Life Care in Nursing Homes with Greater versus Less Palliative Care Knowledge and Practice. J Palliat Med 2015;18:527-34.

16. Al Qadire M. Knowledge of palliative care: an online survey. Nurse Educ Today 2014;34:714-8.

17. Liang L, Zhang G. Research on the status of hospice care in mainland China. Practical Geriatrics 2018;32:20-2.

18. Johnson CE, Singer R, Masso MR, et al. Palliative care health professionals' experiences of caring for patients with advance care directives. Aust Health Rev 2015;39:154-9.

19. Wang XS, Di LJ, Reyes-Gibby CC, et al. End-of-life care in urban areas of China: A survey of 60 oncology clinicians. J Pain Symptom Manage 2004;27:125-32.

20. Jiang Y, Li JY, Liu C, et al. Different attitudes of oncology

Cite this article as: $\mathrm{Wu} \mathrm{X}$, Zhang X, Zhang J, Cui X. Analysis of knowledge, attitude and behavior of oncology medical staff in palliative care. Ann Palliat Med 2020;9(3):985-992. doi: 10.21037/ apm-20-851 clinicians toward truth telling of different stages of cancer. Support Care Cancer 2006;14:1119-25.

21. Bradley SL, Tieman JJ, Woodman RJ, et al. Which online format is most effective for assisting Baby Boomers to complete advance directives? A randomised controlled trial of email prompting versus online education module. BMC Palliative Care 2017;16:43-51.

22. Chover-Sierra E, Martínez-Sabater A, Lapeña-Moñux Y. Knowledge in palliative care of nursing professionals at a Spanish hospital. Rev Lat Am Enfermagem 2017;25:e2847.

23. Xiang YR, Ning XH. Cognitive survey of Chinese clinicians on palliative care. Chinese Medical Sciences Journal 2018;33:221-7. 